(c) American Dairy Science Association, 2006.

\title{
Opinions and Practices of Wisconsin Dairy Producers About Biosecurity and Animal Well-Being
}

\author{
F. G. H. Hoe and P. L. Ruegg ${ }^{1}$ \\ Department of Dairy Science, University of Wisconsin, Madison 53706
}

\begin{abstract}
The objective of this study was to characterize opinions and practices of Wisconsin dairy producers about biosecurity and animal well-being. Wisconsin dairy producers were surveyed using a mailed questionnaire and responder herds were categorized based on the number of lactating cows: very small herds ( $\leq 50$ lactating cows; $\mathrm{n}=279$ ); small herds (51 to 100 lactating cows; $\mathrm{n}=$ 202); medium herds (101 to 200 lactating cows; $n=42$ ); and large herds $(>200$ lactating cows; $n=37$ ). Producers from large herds adopted more biosecurity practices than those from small herds, but biosecurity risks were common. Almost half of the responders indicated that they purchased cattle, but few (49.4\%) performed diagnostic testing of those cattle. The frequency of diagnostic testing and examination of purchased cattle increased with herd size. Producers generally (80\%) believed that they used the "right amount" of antibiotics, but the use of written treatment protocols increased with herd size. Producers from large and medium herds reported much higher usage of computerized (65.7 and $17.5 \%$, respectively) and paper records (42.9 and $22.5 \%$, respectively) compared with producers from smaller herds. Almost all (92.6\%) believed that Johne's disease was an important issue for the dairy industry, but only 9\% had enrolled in the official Wisconsin control program. Most producers (88.6\%) believed that dehorning caused at least a small amount of pain, but the majority (81\%) did not use local anesthetics. Producers minimized risks with which they were most familiar. Drinking raw milk was not considered a human health risk by almost half the responders, whereas bovine spongiform encephalopathy was considered "no risk" to only $37 \%$. Raw milk was consumed by more than $60 \%$, but regular consumption of raw milk decreased from $47.7 \%$ (very small herds) to $24.3 \%$ (large herds); perception of the risk of raw milk increased from $46.2 \%$ (very small herds) to $56.8 \%$ (large herds) with herd size. Larger farms had more knowledge of personal health risks
\end{abstract}

Received July 28, 2005

Accepted December 14, 2005.

${ }^{1}$ Corresponding author: plruegg@wisc.edu related to zoonotic pathogens. Overall, most management practices were associated with herd size, but many beliefs regarding important dairy farm issues were consistent.

Key words: biosecurity, welfare, management, dairy

\section{INTRODUCTION}

The US dairy industry has been very successful in producing high quality food products. Although dairy products are consumed daily, they have been associated with less than $1.5 \%$ of all foodborne disease outbreaks that have been investigated by the Centers for Disease Control (Bean et al., 1996). In spite of this history, consumers are increasingly concerned with the hygiene and quality of food products (Ruegg, 2003). The occurrence of antibiotic residues in milk has historically been an important consumer issue associated with the dairy industry and a number of quality assurance programs have been developed during the last decade to address consumer and industry concerns (Payne et al., 1999; Gibbons-Burgener et al., 2000). The focus of most of these programs has been the assessment of risk factors related to occurrence of antibiotic residues in milk and meat products. Farmers have responded to these educational and regulatory efforts by consistently reducing the occurrence of antibiotic violations. The prevalence of positive test results for bulk milk tankers has steadily declined and $30 \%$ less milk was discarded in fiscal year 2003 as compared with 1999 (Ruegg, 2005).

More recently, the association of specific biological hazards [such as bovine spongiform encephalopathy (BSE) and others] with foods of animal origin has focused consumer attention on animal management practices (Brown et al., 2001). Increased intensity of management on feeding and biosecurity practices may improve farm profitability by lowering the incidence of infectious diseases and improving production efficiency.

The development of quality assurance programs is generally based on adoption of best management practices that address biosecurity and general herd health. In some instances, the results of risk assessments are used to guide recommendations for implementation of specific control practices. Widespread implementation of best management practices requires an understand- 
ing of the beliefs and current practices of dairy producers. The rapid and continuing evolution of the Wisconsin dairy industry (from small farms to large farms) has resulted in a large diversity of herd sizes and tremendous variation relative to adoption of best management practices (USDA, 2002a,c). The objective of this study was to determine selected beliefs and practices of a broad selection of Wisconsin dairy producers.

\section{MATERIALS AND METHODS}

\section{Questionnaire and Mailing}

During September 2004, an 11-page, postage-paid questionnaire was designed and sent to randomly selected WI dairy producers $(\mathrm{n}=1,102)$ using standard survey methodology (Dillman, 1978). Producers were randomly selected using computer generated random numbers from a sampling frame that included addresses of all dairy producers licensed to produce milk in Wisconsin $(\mathrm{n}=16,496)$. The survey included 2 parts: the first section ( $\mathrm{n}=44$ questions) covered current management practices used on the farm and the second section ( $\mathrm{n}=11$ questions) was composed of questions regarding the beliefs about selected dairy farm issues. One week after the initial mailing, a postcard was sent to thank responders and to request that nonresponders return the completed questionnaire. After 3 wk, nonresponders received a second questionnaire that was accompanied by a letter again requesting producer participation.

\section{Statistical Analyses}

Data were entered into a database and checked for typographical errors. Herds were stratified into 4 categories based on the number of lactating cows: very small ( $\leq 50$ lactating cows); small (51 to 100 lactating cows); medium (101 to 200 lactating cows) and large $(>200$ lactating cows). Statistical analyses were performed using PROC FREQ (SAS Institute, 2002). $\chi^{2}$ Tests were performed to test the association between responses (practices and beliefs) and herd size. When herd size was associated with a practice or belief and there was $\geq 10 \%$ difference between the very small and large herds, odds ratios were calculated to determine the odds (of adoption of the practice or belief) of medium and large herds relative to very small and small herds. The level of significance used was 0.05.

\section{RESULTS AND DISCUSSION}

\section{Profile of Responders}

A total of 587 questionnaires (53\%) were returned, indicating that WI dairy producers were interested in the topic of biosecurity and animal well-being. For herds reporting herd size $(\mathrm{n}=560)$, surveys appeared to have been returned from a representative sample of WI dairy herds including very small herds $(\mathrm{n}=279$; $50 \%)$; small herds $(\mathrm{n}=202 ; 36 \%)$; medium herds $(\mathrm{n}=$ $42 ; 8 \%)$; and large herds $(\mathrm{n}=37 ; 7 \%)$. The reported frequency of dairy herd size in WI in 2004 was $40 \%$ (1 to 49 head), $42 \%$ (50 to 99 head), $12 \%$ (100 to 199 head), and 6\% ( $\geq 200$ head; NASS, 2005). The mean number of lactating cows $(93, \mathrm{SD}=169.7)$ was similar to the US average of 93 (USDA, 2002a) and greater than the state average of 78 (NASS, 2005). Herds had similar production (mean rolling herd average: $9,005 \mathrm{~kg}$, SD = 1,747 ) to the national average production (US rolling herd average of 9,295 kg; USDA, 2002a). Responders reported that they produced milk with lower bulk tank SCC $(245,477$, SD $=109,261)$ compared with other herds located in the Midwest. Only 36\% of the herds located in the Midwest have bulk tank SCC less than 299,000 (USDA, 2002c).

\section{Practices and Opinions of Responders}

Purchase of Cattle. The addition of cattle from external sources generally increases the risk of introduction of new diseases. Lactating cows are the highest risk type of animal to purchase because they have more opportunity for previous exposure to contagious pathogens that cause mastitis and other infectious diseases. Similar to a previous national survey (USDA, 2002a), $44 \%$ of WI survey responders reported they had purchased cattle during the $3 \mathrm{yr}$ preceding the survey. The majority of producers from medium (61\%) and large (75\%) herds reported the purchase of cattle compared with $40 \%$ from both very small and small herds. Regardless of herd size, lactating cows were the most common type of animal purchased (Table 1).

Examination of purchased cattle and the use of selected diagnostic tests are often recommended for disease control, but few reported the collection of information about the source of purchased cattle or the use of diagnostic tests (Table 1). As herd size increased, the frequency of diagnostic testing increased; $18.5 \%$ of producers with large operations reported that no diagnostic tests were performed $(P<0.01)$. Overall, the proportion that reported that no diagnostic tests were performed $(51 \%)$ was less than previously reported by USDA (76\%; USDA, 2002a), probably because we included diagnostic testing for mastitis pathogens as an option. Mycobacterium paratuberculosis is one pathogen that may be introduced to dairy herds through the purchase of infected but clinically normal cattle (Sweeney, 1996). There was indication that educational programming for Johne's disease has been somewhat 
Table 1. Practices of Wisconsin producers $(n=243)$ that purchased cattle during 2002, 2003, and 2004

\begin{tabular}{|c|c|c|c|c|c|c|c|}
\hline \multirow[b]{2}{*}{ Question } & \multicolumn{5}{|c|}{ Percentage of responders ${ }^{1}$} & \multirow[b]{2}{*}{$P$} & \multirow[b]{2}{*}{ Odds ratio $^{2}$} \\
\hline & Very small & Small & Medium & Large & Overall & & \\
\hline \multicolumn{8}{|l|}{ Type of cattle purchased } \\
\hline Bred heifers & 37.5 & 41.8 & 76.0 & 66.7 & 46.1 & $<0.01$ & \multirow[t]{3}{*}{$3.8(2.0-7.4)$} \\
\hline Bulls & 25.9 & 26.6 & 20.0 & 11.1 & 23.9 & 0.36 & \\
\hline Lactating cows & 60.7 & 68.4 & 60.0 & 51.9 & 62.1 & 0.45 & \\
\hline \multicolumn{8}{|l|}{ Information about the source of purchased cattle } \\
\hline Bulk tank Mycoplasma status & 7.2 & 7.6 & 20.0 & 48.2 & 13.2 & $<0.01$ & $6.7(3.0-14.7)$ \\
\hline \multicolumn{8}{|l|}{ Diagnostic tests performed on purchased cattle } \\
\hline Johne's disease & 14.3 & 13.9 & 20.0 & 44.4 & 18.1 & $<0.01$ & \multirow{3}{*}{$\begin{array}{l}3.0(1.5-6.0) \\
5.2(2.4-11.5)\end{array}$} \\
\hline Bovine virus diarrhea & 8.9 & 6.3 & 16.0 & 44.4 & 12.8 & $<0.01$ & \\
\hline Bovine leukemia & 4.5 & 3.8 & 4.0 & 14.8 & 5.4 & 0.14 & \\
\hline SCC or California Mastitis Test & 26.8 & 32.9 & 36.0 & 33.3 & 30.5 & 0.70 & \\
\hline Test for Staph. aureus or Strep. agalactiae & 4.5 & 10.1 & 16.0 & 25.9 & 9.9 & $<0.01$ & $4.0(1.7-9.7)$ \\
\hline Herdsperson & 66.1 & 72.2 & 88.0 & 74.1 & 71.2 & 0.17 & \multirow{3}{*}{$2.4(1.2-4.8)$} \\
\hline Cattle dealer & 8.9 & 3.8 & 12.0 & 11.1 & 7.8 & 0.40 & \\
\hline No one & 19.6 & 22.8 & 4.0 & 7.4 & 17.7 & 0.08 & \\
\hline \multicolumn{8}{|l|}{ Type of exam before commingling } \\
\hline Body temperature & 7.1 & 10.1 & 12.0 & 18.5 & 9.9 & 0.34 & \multirow{5}{*}{$1.9(1.0-3.6)$} \\
\hline BCS & 33.0 & 45.6 & 60.0 & 44.4 & 41.2 & 0.06 & \\
\hline Lameness & 33.9 & 43.0 & 48.0 & 44.4 & 39.5 & 0.41 & \\
\hline Reproductive exam & 42.9 & 49.4 & 48.0 & 74.1 & 49.0 & 0.04 & \\
\hline Other & 8.0 & 3.8 & 16.0 & 11.1 & 7.8 & 0.21 & \\
\hline
\end{tabular}

${ }^{1}$ Very small herds = $\leq 50$ lactating cows; small herds = 51 to 100 lactating cows; medium herds = 101 to 200 lactating cows; large herds = $>200$ lactating cows.

${ }^{2}$ Calculated only for outcomes where a significant association was detected and $\geq 10 \%$ difference between very small herds and large herds; comparison is odds of medium and large herds compared with small and very small herds (95\% confidence interval).

effective. More WI responders (18\%) reported that they tested purchased cattle for Johne's disease compared with a previous report (10\%; USDA, 2002a). Almost $40 \%$ of all responders indicated that they inquired about the herd status of Johne's disease before purchasing cattle, but producers of large herds were 3 times more likely to test cattle for Johne's disease before purchase compared with those with smaller herds.

Screening of milk samples for contagious mastitis pathogens is another commonly suggested biosecurity practice and $51.9 \%$ of all producers inquired about the bulk tank SCC of the herd of origin for purchased cattle (Table 1). Similar to previous reports (USDA, 2002a), concern about Mycoplasma spp. mastitis was markedly higher in the larger herds (48.2\%), with producers with medium and large herds 7 to 8 times more likely to ask about or perform diagnostic testing for Mycoplasma. Overall, WI producers responding to this survey indicated more concern about mastitis status of purchased cattle compared with previous national data (USDA, 2002a). The USDA survey was based on farms that bought cattle during 2001. Our study was conducted in the fall of 2004 and it is possible that concern about the milk quality has increased, as was observed between the 1996 and the 2001 National Animal Health Monitoring System (NAHMS) studies (USDA, 2002b). In general, USDA (2002a) data indicated that the percentage of operations that required SCC testing and milk culture from purchased animals increased as the size of operation increased, which is supported by our results.

There was indication that large producers (44.4\%) have more access to veterinary services than other sized farms $(-15 \%)$. The use of a veterinarian to examine purchased cattle before they entered the herd and the proportion of herds that performed reproductive exams was highly associated with herd size (Table 1). It is possible that smaller producers are aware of the importance of such practices, but financial constraints or simply less frequent contact with veterinarians may be limiting factors for implementation of preventive measures.

Mastitis Control and Treatment Practices. Producers agreed that cleanliness of the cow bed is important for the control of mastitis and only $3 \%$ believed that it was not related to control of mastitis. However, 
when asked about the frequency of changing bedding in maternity pens, $44 \%$ reported that bedding was only changed several times per week. Medium (50\%) and large herds $(51.4 \%)$ were 3 times more likely to change bedding even less frequently compared with small $(34.1 \%)$ and very small (23\%) herds. Stalls became increasingly contaminated with bacteria over the course of $1 \mathrm{wk}$ and stall cleanliness was associated with the number of bacteria in samples obtained from sand and sawdust cow beds (Zdanowicz et al., 2004). In that study, bacterial counts in bedding and teat ends were associated, suggesting that bedding cleanliness is related to contamination of teats and risk of mastitis infection. Although producers in this survey agreed that cleanliness of bedding was important for mastitis control, it appeared difficult to implement frequent bedding changes. Depending on specific farm conditions, certain management practices are not easily changed, even when managers are aware of effective control measures.

Most mastitis control practices were significantly associated with herd size and reflected differences in milking systems or animal housing (Table 2). A few producers from medium $(7.1 \%)$ and large $(10.8 \%)$ herds had a different milking facility for mastitic cows (odds ratio; $\mathbf{O R}=7.7)$ and responders from medium $(47.6 \%)$ and large $(35.1 \%)$ herds were more likely to disinfect milking units after milking cows with clinical mastitis $(\mathrm{OR}=$ $3.3)$ than smaller herds. Producers from small (31.7\%) and very small $(22.7 \%)$ herds were more likely to use a different milking unit or to milk mastitic cows last (33.7 and 52\%, respectively), probably because most of them milked cows in a stall barn and they had the ability to selectively use a milking unit on specified cows.

The use of diagnostic tests for clinical mastitis was associated with herd size (Table 2). A much higher proportion of the largest herds (38.9\%) were culturing all clinical cases of mastitis as compared with other herdsize strata.

In a similar fashion, usage and frequency of bulk tank culturing was associated with herd size (Table 2). Medium and large herds were 2 to 3 times more likely to examine bulk tank milk for mastitis pathogens as compared with smaller herds; $49 \%$ of the smallest herds had never submitted a bulk tank milk sample for microbiological analysis. Ease of access to these diagnostic methods may be related to herd size because a number of milk processors provide these services for their farms and it is possible that larger farms are approached more frequently by field support staff offering these services.

Responders were asked to characterize how they felt about the amount of antibiotics that were used on their farms. Most producers (80\%) believed that they were using the "right amount" of antibiotics and an equal proportion (6\% each) believed that they used "more antibiotics than they should" or were "not using enough antibiotics." Similar to results of Zwald et al. (2004), 8\% indicated that no antibiotics were used on their farm.

Written treatment protocols are recommended to help bring conformity to treatment practices. It is reasonable to assume that the need for such protocols would increase with herd size because more people may be involved in treatment decisions. This assumption was confirmed in our survey because the presence of a written treatment protocol for mastitis was highly associated with herd size $(P<0.01)$. Most responders from large herds $(75 \%)$ reported that they had a written treatment protocol for mastitis as compared with 29 , 21 , and $12 \%$ from medium, small, and very small herds, respectively. Regardless of herd size $(P=0.41)$, about $60 \%$ of treatment protocols were written by a veterinarian, whereas about $33 \%$ were written by farm managers, and $4 \%$ were a collaborative effort. Less than $1 \%$ of treatment protocols originated from drug companies.

Most producers used a variety of methods to record antibiotic treatments for mastitis (Table 2). Herd size was associated with the use of computers to record treatments $(\mathrm{OR}=19.8)$. A California survey reported that about 35 and $71 \%$ of the herds used computer and paper records to record drug treatments, respectively (Payne et al., 1999). Whereas 66\% of producers with large herds reported they recorded antibiotic treatments in computers, the proportion from other herd size categories fell to $18 \%$ (medium herds) and only 3 to $4 \%$ for small and very small herds. These findings imply that research that relies on computer records to assess antibiotic treatments will likely result in serious underestimation of usage. Similar to previous results (Payne et al., 1999), about 3\% from large herds reported that they did not have any record of antibiotic treatments for mastitis treatments. There is some indication that a renewed emphasis on educational programs regarding antibiotic usage requirements should be targeted toward smaller herds because about 15 to $19 \%$ of other herd size strata indicated they did not have any records of antibiotic treatments for cows that received antibiotics (Table 2).

Control of Johne's Disease. Johne's disease is an important disease of dairy cattle and results in reduced profitability for herds that have a high prevalence of infection. Economic losses result from reduced milk production and it is estimated that if $>10 \%$ of the cull cows have clinical signs, the economic impact on the herd is $\$ 227$ per cow (NAHMS, 1997). The continuing controversy about zoonotic potential of Johne's disease has increased the importance of control programs (Wapenaar et al., 2003). Independent of herd size $(P=0.15)$, more than $90 \%$ of responders agreed with the statement 
Table 2. Practices of responders related to milking mastitic cows, frequency of microbiological culturing, and type of records used

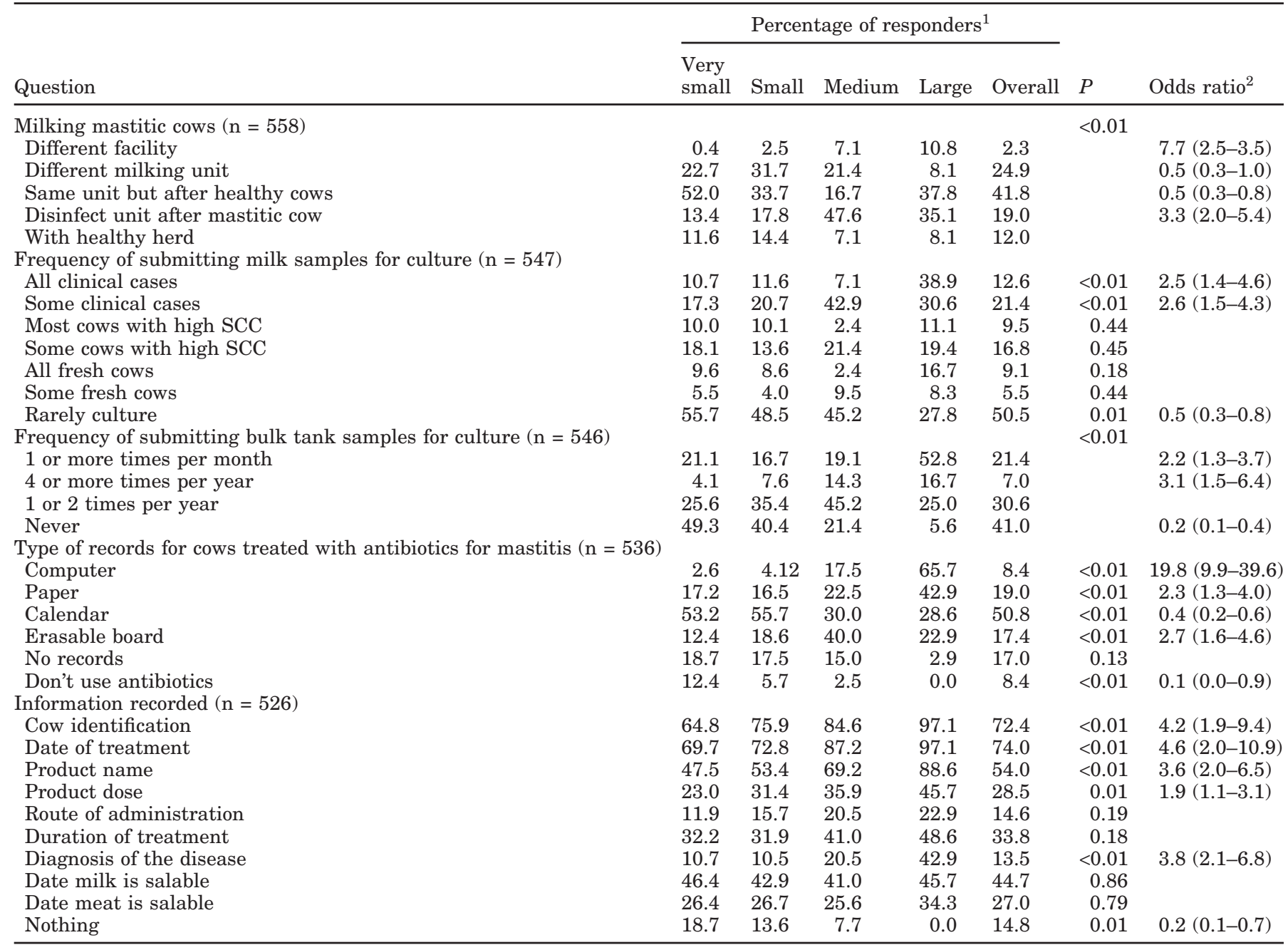

${ }^{1}$ Very small herds $=\leq 50$ lactating cows; small herds = 51 to 100 lactating cows; medium herds = 101 to 200 lactating cows; large herds = $>200$ lactating cows.

${ }^{2}$ Calculated only for outcomes where a significant association was detected and $\geq 10 \%$ difference between very small herds and large herds; comparison is odds of medium and large herds compared with small and very small herds (95\% confidence interval).

"Johne's disease was an important issue for the dairy industry." Paradoxically, relatively few producers were enrolled in the voluntary control program administered by state regulatory officials. Participation in the WI control program was associated with herd size $(P<$ 0.01 ). Of responders, $6,8,12$, and $32 \%$ of very small, small, medium, and large producers, respectively, indicated they were enrolled in the official WI control program. Medium and large herds were more likely enrolled in the WI control program $(\mathrm{OR}=3.8)$. Of producers participating in the program $(n=53)$, the herd status (percentage of tested animals that tested positive) was not associated with herd size strata $(P=0.93)$. Of participants in the program, 22, 20,24, and 4\% indicated that no animals tested positive, $<5 \%$ of animals tested positive, 5 to $15 \%$ of animals tested positive, or
$>15 \%$ of animals tested positive, respectively. Although the proportion enrolled in the official control program was low, it is higher than a previous estimate (NAHMS, 1997). In 1996, the NAHMS estimated that $<1.0 \%$ of the dairy operations in the United States were enrolled in a Johne's disease certification program (NAHMS, 1997).

Of all producers (irrespective of participation in the voluntary control program), herd size was associated with detection of a Johne's disease test-positive cow and medium and large herds were 5.6 times more likely to have experienced a Johne's disease test-positive cow (Table 3). The overall prevalence of the occurrence of one or more Johne's disease test-positive cows (28\%) was higher than previous estimates (Table 3) of $19.9 \%$ (NAHMS, 1997). 
Table 3. Practices of responders related to animals that tested positive for Johne's disease and general control practices.

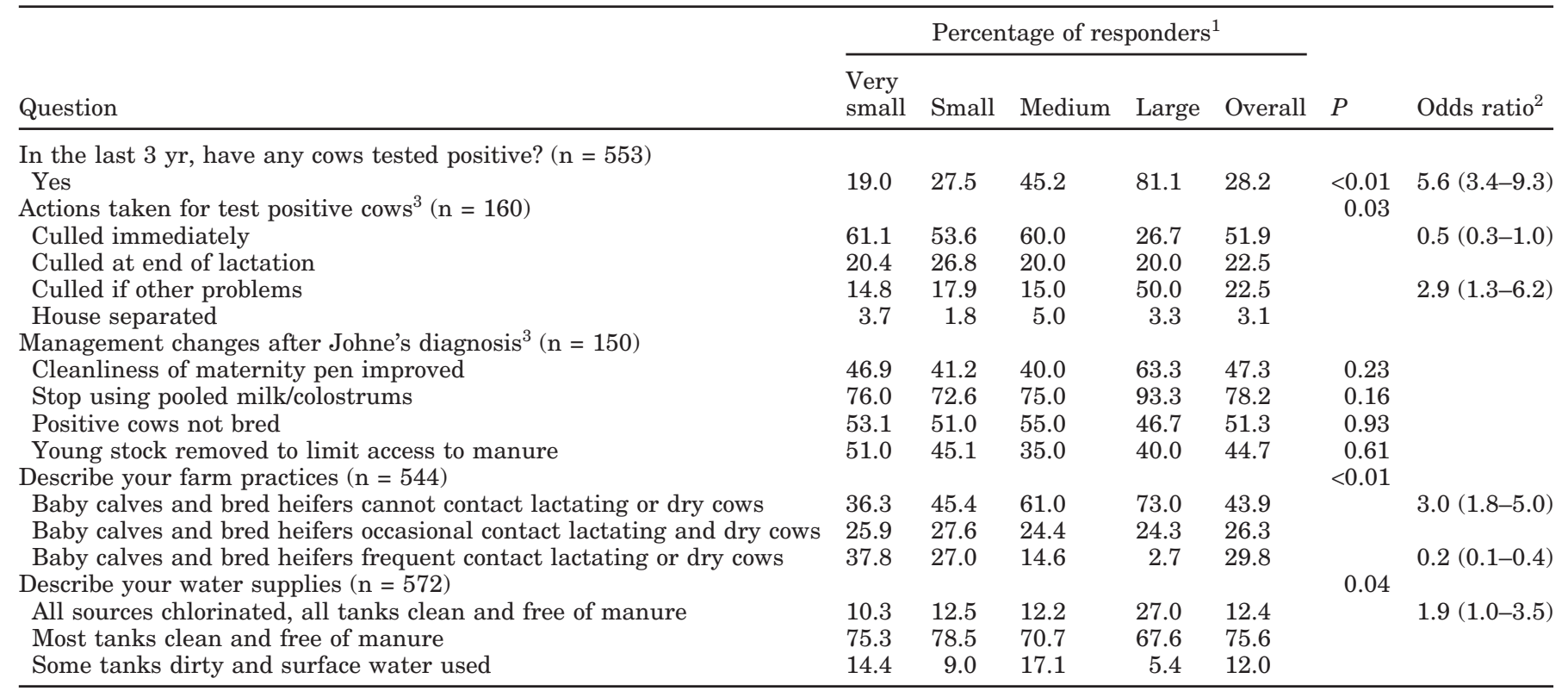

${ }^{1}$ Very small herds $=\leq 50$ lactating cows; small herds = 51 to 100 lactating cows; medium herds = 101 to 200 lactating cows; large herds = $>200$ lactating cows.

${ }^{2}$ Calculated only for outcomes where a significant association was detected and $\geq 10 \%$ difference between very small herds and large herds; comparison is odds of medium and large herds compared with small and very small herds (95\% confidence interval).

${ }^{3}$ For responder herds that reported test positive cows.

Control of Johne's disease is based on adoption of management procedures that minimize exposure of calves to infected manure. Responders were asked about actions taken with cows that tested positive for Johne's disease. Many of them reported that they culled most Johne's disease positive cows, but producers from small herds culled the cows immediately $(61.1 \%)$ and responders from large herds culled the cows only if other problems were present (50\%; Table 3). Similar management changes were taken for all herd sizes after diagnosis of one or more cows that tested positive for Johne's disease $(P>0.16)$. The most frequently reported management change was to stop feeding pooled milk or colostrum to calves. This strategy is highly recommended and is probably one of the easier management changes to implement. A study of implementation of a biosecurity program on herds from New York State reported that the use of milk replacer and colostrum obtained from Johne's disease negative cows was more frequently implemented when compared with other management practices (Wapenaar et al., 2003).

The isolation of calves and bred heifers from contact with mature animals is an important management practice that helps reduce the spread of infectious disease among age groups and this survey included questions about the amount of contact between adult cows and calves and bred heifers. Contact between age groups was associated with herd size, but $43.9 \%$ indi- cated that calves and heifers did not have any contact with lactating or dry cows (Table 3). In a previous nonrandom study of 99 conventional US dairy farms, $13 \%$ of preweaned calves had no contact with other animals and only $10 \%$ of the weaned calves had no contact with other animals (Zwald et al., 2004). Nationally, 81.3\% of the heifers less than 12 mo old had no direct contact with adult cows (NAHMS, 1997).

Animal Housing and Feeding Practices. Almost all producers, regardless of herd size $(P>0.17)$, believed that animal housing on their farm provided "good comfort." The housing was characterized as providing "good comfort" for milking cows (83\%), dry cows (78\%), maternity pen $(72 \%)$, bred heifers $(80 \%)$, and heifer calves $(82 \%)$.

As expected, many characteristics of animal housing were associated with herd size $(P<0.01)$. Individual calving pens were uniformly used by about $43 \%$ of producers. Responders from medium (34.1\%) and large (43.2\%) herds were 7.2 times more likely to report the use of group pens relative to small (12.9\%) and very small (4.1\%) herds. The overall proportion that reported that the calving pen was used only for calving (50\%) was very similar to another survey (53\%; USDA, 2002a).

Many farms do not include sufficient space for housing of animals with special needs and it was reported that sick cows were housed together with fresh cows in about $22 \%$ of California dairy herds (Payne et al., 1999). 


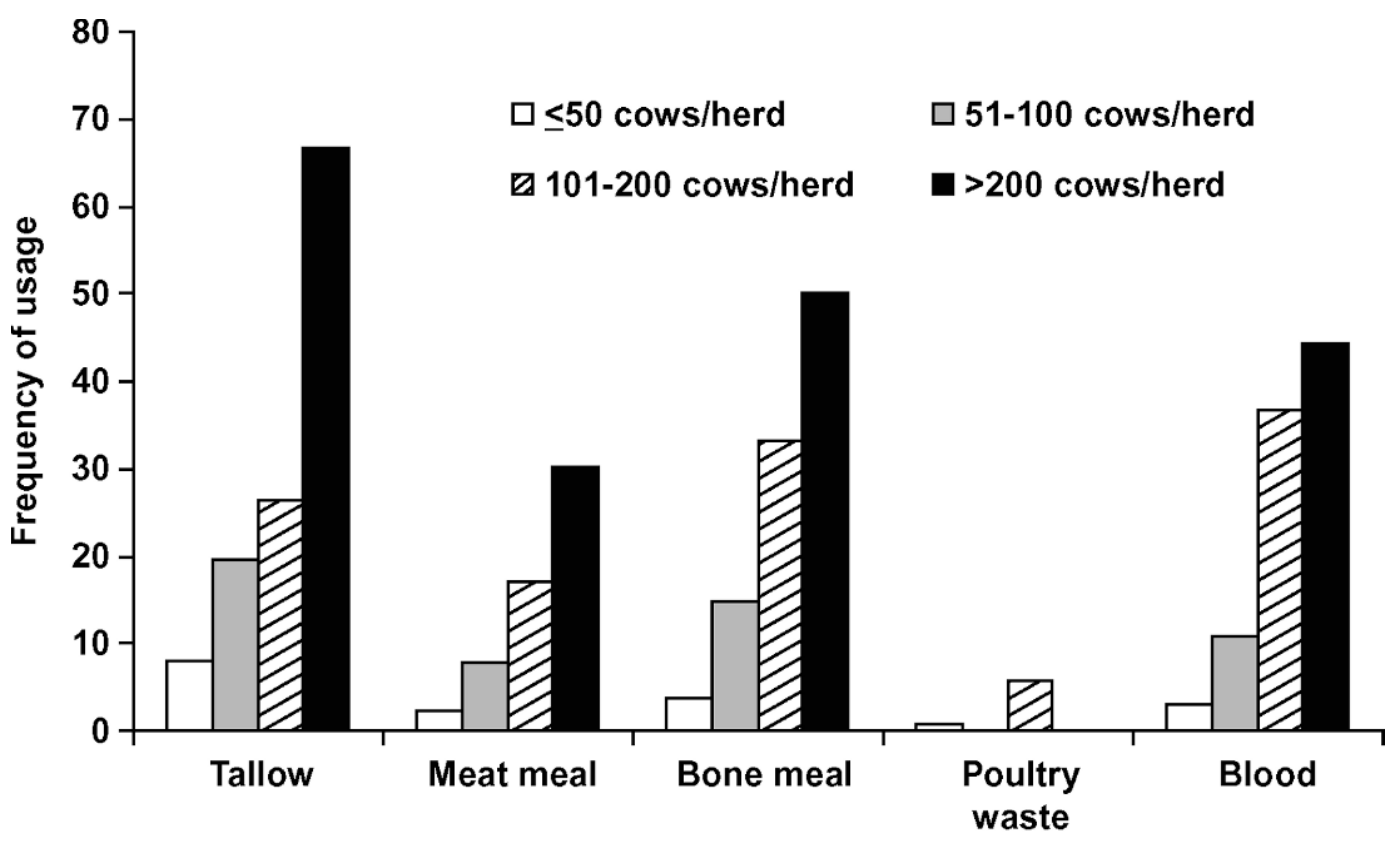

Type of product

Figure 1. Frequency of reported usage of animal products (tallow, nonruminant meat and bone meal, poultry waste, and blood) in the diet by herd size category according to number of lactating cows per herd.

In the current study, only $11 \%$ reported that a calving pen was used to house both parturient and sick cows. However, most $(69 \%)$ reported that sick cows were housed together with healthy milking cows. This practice was strongly associated with herd size $(P<0.01)$, with $76,73,48$, and $16 \%$ of responders from very small, small, medium, and large herds, respectively, reporting this practice. Producers are aware of the need to separate sick and healthy animals and increasingly adopted the practice as herds expanded their housing facilities.

The use of ruminant-based protein sources in the animal diet is prohibited because of concerns about transmission of diseases such as Salmonella (McChesney et al., 1995) and BSE (NAHMS, 2002). In 1997, the FDA prohibited the use of ruminant protein in feeds to cows; however, nonruminant protein sources are still allowed. In this survey, producers were asked about the frequency that selected products were included in cow diets. The overall reported usage of nonruminant products was: tallow (17\%); nonruminant meat meal $(7 \%)$; nonruminant bone meal $(13 \%)$; poultry waste $(<1 \%)$; and blood meal (11\%). Except for poultry waste, the frequency of reported usage of animal products in the diet increased with herd size $(P<0.01$; Figure 1$)$. Smaller producers are less likely to purchase commodities and it is possible that smaller producers were unaware of animal by-products that were present in purchased feedstuffs. Wisconsin farmers that responded to this survey reported similar usage of animal by-products as compared with a previous survey of California producers (Payne et al., 1999), in which 23\% of the producers used bone meal, feather meal, blood meal, or tallow.

Dehorning, Euthanasia, and Sale of Sick Animals. Ensuring the well-being of dairy animals is an important issue in the dairy industry and producers were questioned about several potentially painful management practices. Some dehorning practices are known to increase plasma cortisol levels and are considered associated with pain and stress. The administration of local analgesics has been shown to reduce plasma cortisol levels for about 2 to $3 \mathrm{~h}$ after dehorning (Graf and Senn, 1999). Producer opinions about the amount of pain that calves experience during dehorning were independent of herd size strata (Table 4). About $80 \%$ believed that dehorning calves involved at least a "little amount of pain" and 50\% believed that dehorning caused "moderate" or "a lot" of pain. In spite of these beliefs, only $18 \%$ reported the use of local anesthetics or tranquilizers when dehorning (Table 4). Responses to dehorning questions were generally consistent across herd size, which may indicate a generalized lack of awareness of alternatives.

Farmers were asked several questions related to euthanasia practices of animals that were morbidly ill. Thirty-two percent indicated that they had not required 
Table 4. Opinion of responders about pain experienced by calves during dehorning, frequency of use of local anesthesia, and practices related to euthanasia

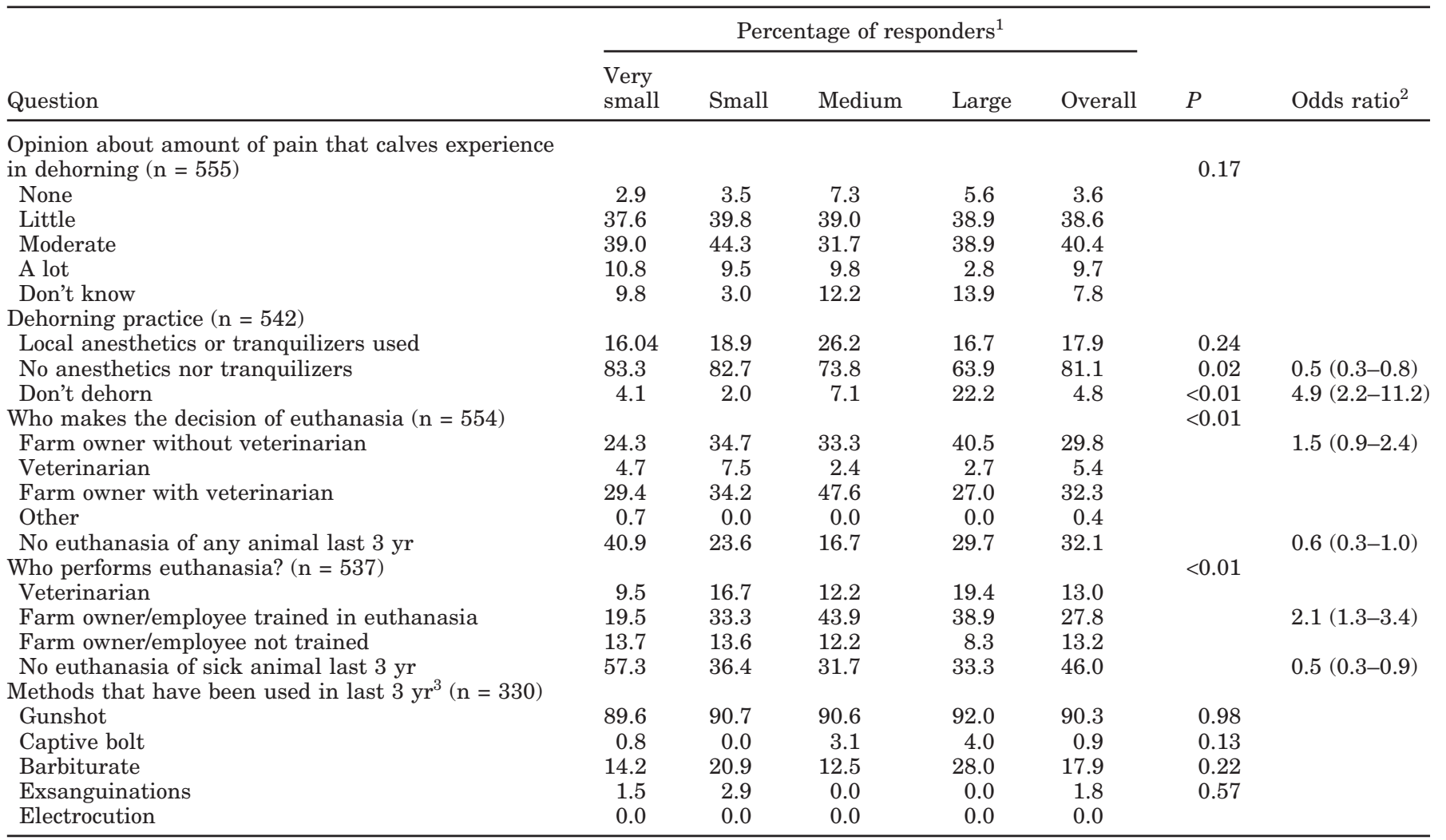

${ }^{1}$ Very small herds $=\leq 50$ lactating cows; small herds = 51 to 100 lactating cows; medium herds = 101 to 200 lactating cows; large herds = $>200$ lactating cows.

${ }^{2}$ Calculated only for outcomes where a significant association was detected and $\geq 10 \%$ difference between very small herds and large herds; comparison is odds of medium and large herds compared with small and very small herds (95\% confidence interval).

${ }^{3}$ Only for those who answered that euthanasia was performed within the last $3 \mathrm{yr}$.

euthanasia of any animal during the preceding $3 \mathrm{yr}$ (Table 4). Responders from very small and small farms were less likely to report that they performed euthanasia of sick animals as compared with larger herds (Table 4). Veterinarians were consulted about euthanasia decisions in $32.3 \%$ of the cases and were consulted less frequently in larger herds (27\%). The use of gunshot was, by far, the most common method of euthanasia (Table 4). When performed by adequately trained personnel, gunshot is an approved method of euthanasia, but its wide use and the infrequent participation of veterinarians raise concerns about both human safety and adequacy of training of persons performing the process.

This survey indicated that additional educational efforts of producers regarding sale of cull dairy animals are necessary. Of responders, $42 \%$ indicated that they did not know the BCS of cattle that were sold for slaughter. The practice of examining cattle before shipment was not associated with herd size $(P=0.53)$. Overall, most producers indicated that "all cull cows were visu- ally examined and cows with disorders were not shipped" (47\%) or "some cows were visually examined, most did not receive physical exams and some sick cows were shipped" (40\%). However, $12 \%$ indicated that "sick cows are routinely shipped and animals are not examined before shipment." Condemnation of cull cows was more likely to occur in large herds (69\%) compared with very small (16\%) and small herds (24\%), and $22 \%$ from large herds reported preslaughter condemnation $(P<$ $0.01)$. Results for the large herds were similar to results of California herds that indicated $71 \%$ of dairies had carcasses condemned because of infection or illness (Payne et al., 1999).

General Biosecurity Risks for the Herd. Farmers were asked their opinion about the level of biosecurity risk posed by potential farm visitors (Figure 2). In general, biosecurity risks of farm visitors were perceived appropriately. People removing dead stock were more frequently considered moderate or high biosecurity risks and foreign visitors were more frequently considered as low risk (Figure 2). Responders from medium 


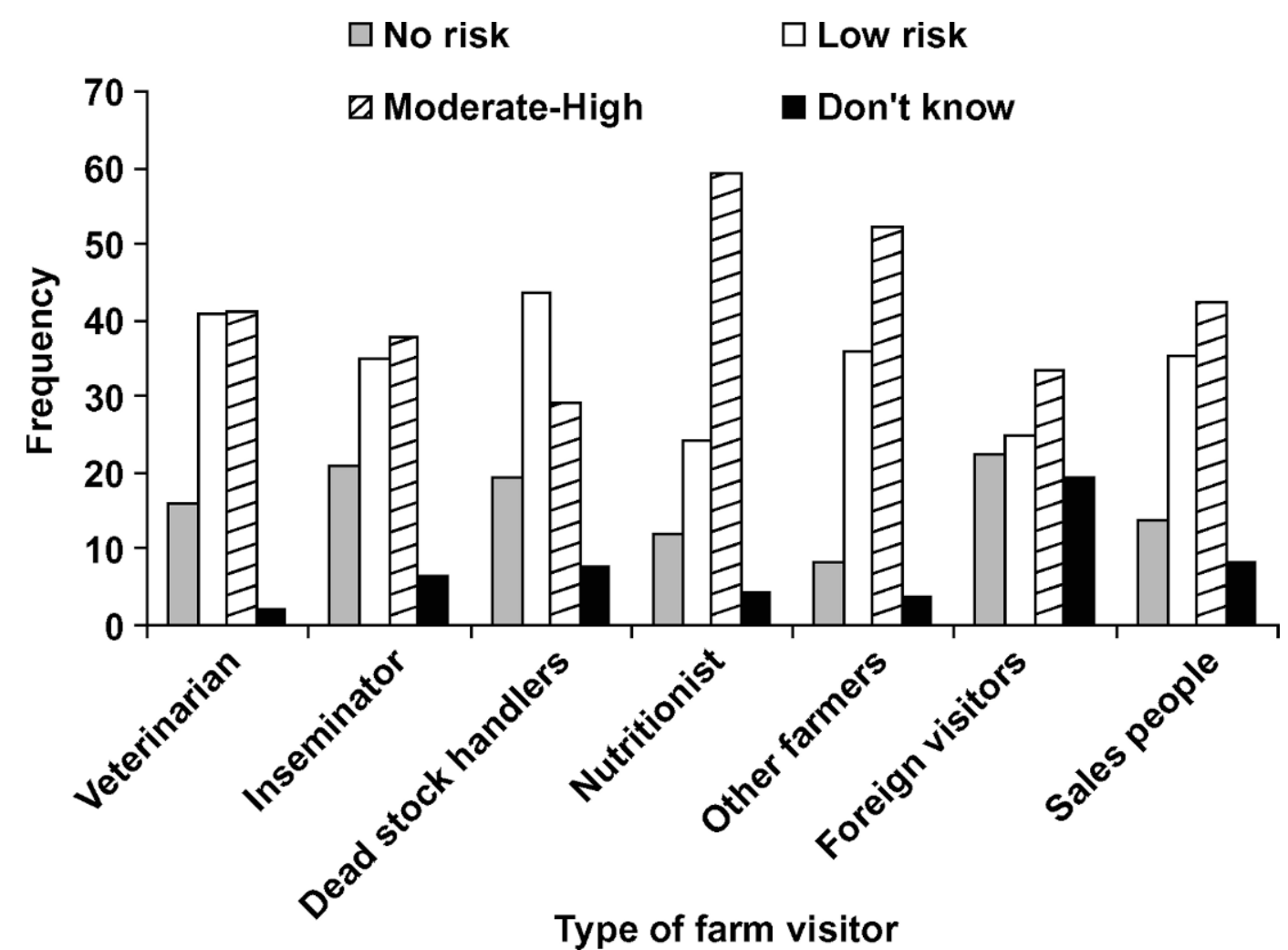

Figure 2. Perception of biosecurity risk of different farm visitors to cattle in farm.

and large farms were more likely to perceive that nutritionists $(P<0.01)$, other farmers $(P<0.05)$, and foreign visitors $(P<0.01)$ posed a risk to their farms compared with smaller herds, probably because smaller herds are less likely to encounter these visitors to their farms (data not shown).

Veterinarians visited almost all farms (91\%) and almost all (93\%; $P=0.99)$ reported that veterinarians washed their boots or wore new disposable boots every time they visited the farm. This practice was performed only on some visits (3\%) or never (3\%) by a minority of veterinarians. Inseminators visited fewer farms (67\%) and $88 \%(P=0.55)$ indicated that inseminators always cleaned their boots or wore new disposable boots. Nutritionists visited $73 \%$ of farms and appeared less attentive to boot cleanliness. Only 50\% indicated that nutritionists washed or wore clean disposable boots at every visit, but the practice was more common $(P<0.01)$ in large herds. Relatively few veterinarians (17\%), inseminators $(3 \%)$, or nutritionists $(4 \%)$ changed coveralls before every visit to the farm. Likewise, $57 \%$ indicated that most animal handlers on the farm washed their boots, but did not change coveralls after handling a sick animal. This practice was not associated with herd size $(P=0.28)$. Thus, in general, dairy producers and farm consultants were more likely to wear clean boots (70.6 and $63.2 \%$, respectively) than clean clothes (13.5 and $8.1 \%$, respectively) and larger farms were more aware of the need for such practices than smaller herds. In large herds, $10.8 \%$ of producers reported that boots and coveralls were not changed or washed by them compared with $23.9 \%$ of producers with very small herds.

Perception of Human Health Hazards. Responders were asked their opinion about the level of risk posed to their own families related to specified farm practices or diseases (Figure 3). The sale of raw milk or raw milk products is not allowed in WI because consumption of raw or inadequately pasteurized milk has been associated with several outbreaks of enteric infections associated with pathogens such as Salmonella spp. (Ryan et al., 1987), Listeria monocytogenes (Linnan et al., 1988), and others. A previous survey of producers from eastern South Dakota and western Minnesota reported that $60 \%$ of the dairy producers consumed raw milk; of those that consumed raw milk, $26.6 \%$ had one or more pathogenic bacteria isolated from their bulk tank milk (Jayarao and Henning, 2001). A similar proportion of responders reported consumption of raw milk in our survey. Raw milk or raw milk products were never consumed by $39 \%$ of responders, but $17 \%$ reported 


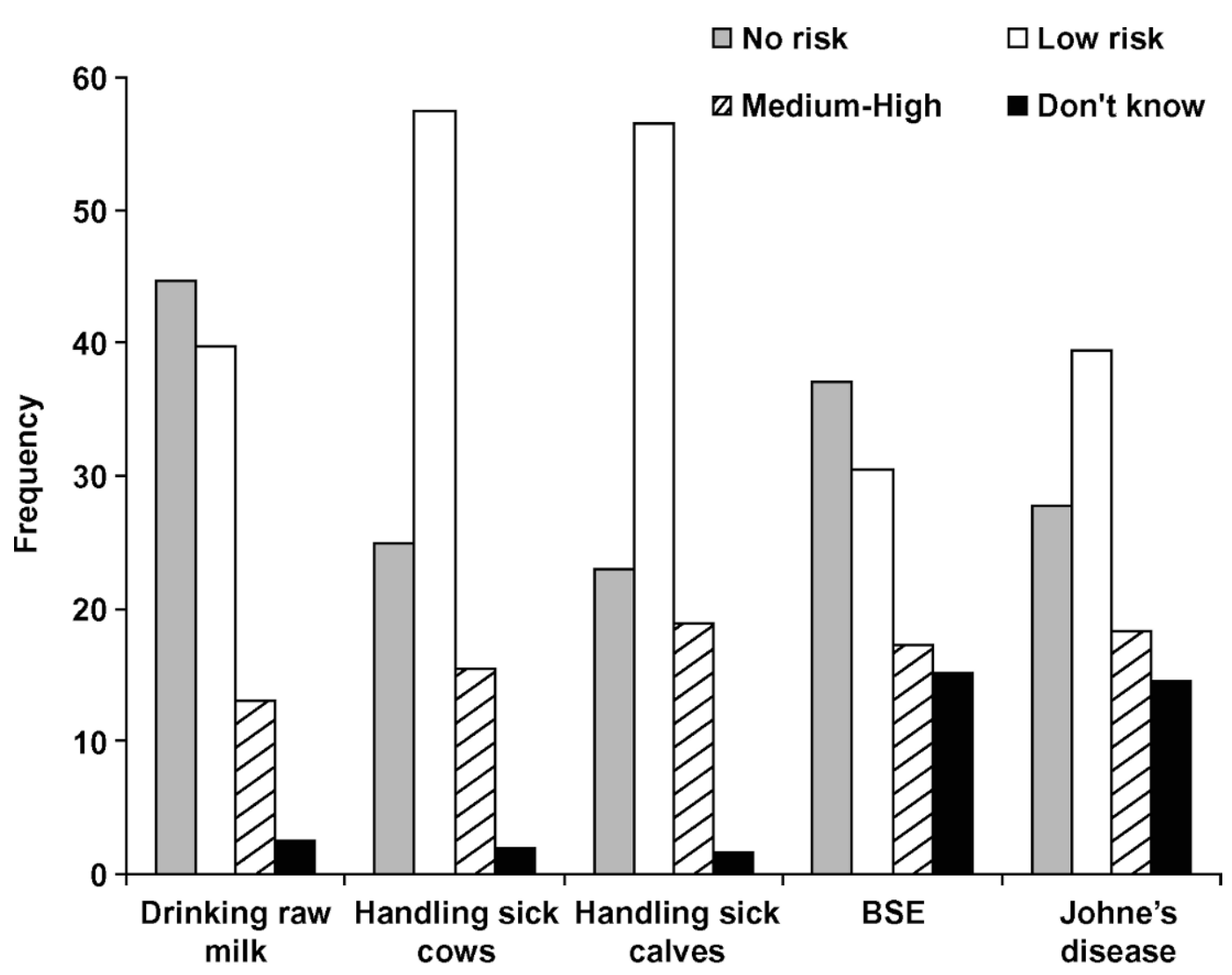

\section{Practice or Disease}

Figure 3. Responder's perception of risk of practices (drinking raw milk, handling sick cows or sick calves) and diseases (bovine spongiform encephalopathy and Johne's disease) to the responder's family.

occasional consumption by people associated with the farm, $40 \%$ reported regular consumption by people associated with the farm, and 5\% reported regular consumption by people outside of the farm. Larger farms had more knowledge of personal health risks related to zoonotic pathogens. For example, $35.1 \%$ of the producers from large herds believed that there is no risk in drinking raw milk as compared with $50.5 \%$ of the producers from very small herds. Opinions about personal health risks related to drinking raw milk were significantly associated with herd size $(P<0.01)$. Fewer medium $(50 \%)$ and large $(37.8 \%)$ herds consumed raw milk compared with small (58.7\%) and very small $(68.1 \%)$ herds $(\mathrm{OR}=0.6)$ and producers from those herds were more likely to consider drinking raw milk a risk to human health $(\mathrm{OR}=2.9)$ when compared with small and very small herds.

Microbes present in manure may be infectious to other animals or farm workers (Pell, 1997). Asymptomatic cows can shed Salmonella in feces during periods of stress (House and Smith, 1998). Shedding from carrier animals awaiting slaughter can cause a significant increase in the likelihood that carcasses emerging from the slaughterhouse will be contaminated with Salmonella, and may contribute to the occurrence of outbreaks of human salmonellosis (Ekperigin and Nagaraja, 1998). In our survey, less than half (41\%) believed that farm workers could contract diseases by exposure to cow manure, but $15 \%$ reported that Salmonella had been isolated at least once from their herd $(P<0.01)$. This proportion is less than the proportion reported by the NAHMS (2003) for Midwest region dairies (25.6\%). The knowledge and occurrence of several pathogens with zoonotic potential was associated with herd size $(P<0.01)$. All responders from large herds were aware of Salmonella, but $23 \%$ of responders from very small herds indicated that they did not know what Salmonella was.

The impact of $L$. monocytogenes on public health has been recognized for at least $20 \mathrm{yr}$. Ingestion of food contaminated with $L$. monocytogenes can cause flu-like symptoms in healthy humans, but for the immunocom- 
promised or pregnant individuals, listeria can result in a severe clinical infection in the form of meningitis, septicemia, or abortion (Schlech, 1997). Approximately $5 \%$ of the 9,000 annual deaths resulting from food poisoning can be attributed to listeriosis (Cooper and Walker, 1998). Prevalence of listeria in raw milk and a variety of dairy products varies between 0.5 and $65 \%$ in Europe (Lundin et al., 2004). One large outbreak of listeriosis in North America occurred in California in 1985 (Linnan et al., 1988). This outbreak was traced to the consumption of soft cheese and involved 142 individuals. In our survey, 54\% reported they had never observed symptoms of listeria nor had an animal diagnosed with the disease. Many (43\%) did not know what listeria was, especially responders from small (44\%) and very small (46\%) herds compared with $23 \%$ of producers with large herds; $P<0.01$.

\section{CONCLUSIONS}

Most management practices were associated with herd size and probably reflected differences in facilities and resources among responders from various herd size strata. Producers from large herds adopted more biosecurity practices than did those from small herds. Biosecurity risks were prevalent. Almost half indicated that they purchased cattle, but few performed diagnostic testing of those cattle. Larger farms were either more aware of biosecurity risks or more able to undertake preventive measures because the frequency of diagnostic testing (OR > 3.0) and examination ( $\mathrm{OR}=1.9)$ of purchased cattle increased with herd size compared with smaller herds. Producers with larger herds performed mastitis control procedures more frequently; $49 \%$ of producers of very small herds had never submitted a bulk tank milk sample for microbiological analysis.

Producers generally believed that they used the "right amount" of antibiotics, but this survey indicated that more effective methods to standardize and record treatments should be developed. Widespread underreporting of antibiotic usage in computerized record systems indicates that analysis of herd computer records will result in underestimates of antibiotic usage. Some widely held opinions of producers were not in agreement with their practices. Producers were highly aware of the importance of Johne's disease, but few were enrolled in the official WI control program. Most producers believed that dehorning caused at least a small amount of pain, but the majority of responders did not use local anesthetics.

Responders minimized risks with which they were most familiar. Drinking raw milk was not considered a human health risk by almost half, whereas BSE was considered "no risk" to 37\%. Raw milk was consumed by more than $60 \%$, but consumption of raw milk decreased and perception of the risk of raw milk increased with increasing herd size. Larger farms had more knowledge of personal health risks related to zoonotic pathogens. Overall, most management practices were associated with herd size, but many beliefs of responders were consistent.

\section{REFERENCES}

Bean, N. H., J. S. Goulding, C. Lao, and F. J. Angulo. 1996. Surveillance for foodborne-disease outbreaks-United States, 19881992. Morbid. Mortal. Wkly. 45:1-73.

Brown, P., R. G. Will, R. Bradley, D. M. Asher, and L. Detwiler. 2001. Bovine spongiform encephalopathy and variant Creutzfeldt-Jakob disease: Background, evolution, and current concerns. Emerg. Infect. Dis. 7:6-14.

Cooper, J., and R. D. Walker. 1998. Listeriosis. Vet. Clin. North Am. Food Anim. Pract. 14:113-125.

Dillman, D. A. 1978. Mail and telephone surveys: The total design method, ed. Wiley, New York, NY.

Ekperigin, H. E., and K. V. Nagaraja. 1998. Salmonella. Vet. Clin. North Am. Food Anim. Pract. 14:17-29.

Gibbons-Burgener, S. N., J. B. Kaneene, J. W. Lloyd, and R. J. Erskine. 2000. Influence of the milk and dairy beef quality assurance program on dairy farm drug management practices. J. Am. Vet. Med. Assoc. 216:1960-1964.

Graf, B., and M. Senn. 1999. Behavioural and physiological responses of calves to dehorning by heat cauterization with or without local anaesthesia. Appl. Anim. Behav. Sci. 62:153-171.

House, J. K., and B. P. Smith. 1998. Current strategies for managing Salmonella infections in cattle. Vet. Med. 93:756-764.

Jayarao, B. M., and D. R. Henning. 2001. Prevalence of foodborne pathogens in bulk tank milk. J. Dairy Sci. 84:2157-2162.

Linnan, M. J., L. Mascola, X. Dong Lou, V. Goulet, S. May, C. Salinem, D. W. Hird, M. L. Yonekura, P. Hayes, R. Weaver, A. Audurier, B. D. Plikaytis, S. L. Fannin, A. Kleks, and C. V. Broome. 1988. Epidemic listeriosis associated with Mexican-style cheese. N. Engl. J. Med. 319:823-828.

Lundén, J., R. Tolvanen, and H. Korkeala. 2004. Human listeriosis outbreaks linked to dairy products in Europe. J. Dairy Sci. 87(E. Suppl.):E6-E11.

McChesney, D. G., G. Kaplan, and P. Gradner. 1995. FDA survey determined Salmonella contamination. Feedstuffs (Feb. 13):20.

NAHMS. 1997. Johne's Disease on U.S. dairy operations. \#N245.1097. USDA:APHIS:VS, CEAH, National Animal health Monitoring System, Fort Collins, CO.

NAHMS. 2002. Bovine Spongiform Encephalopathy. USDA:APHIS:VS, CEAH, National Animal Health Monitoring System, Fort Collins, CO.

NAHMS. 2003. Salmonella and Campylobacter on U.S. dairy operations. \#N401.1203. USDA:APHIS:VS, CEAH, National Health Monitoring System, Fort Collins, CO.

NASS. 2005. Wisconsin 2005 Agricultural Statistics. Madison, WI.

Payne, M., C. M. Bruhn, B. Reed, A. Scearce, and J. O’Donnell. 1999. On-farm quality assurance programs: A survey of producer and industry leader opinions. J. Dairy Sci. 82:2224-2230.

Pell, A. N. 1997. Manure and microbes: Public and animal health problem? J. Dairy Sci. 80:2673-2681.

Ruegg, P. L. 2003. Practical food interventions for dairy production. J. Dairy Sci. 86(E. Suppl.):E1-E9.

Ruegg, P. L. 2005. Relationship between bulk tank milk somatic cell count and antibiotic residues. Pages 28-35 in Proc. 44th National Mastitis Council Mtg., Orlando, FL. Natl. Mastitis Counc., Inc., Verona, WI.

Ryan, C. A., M. K. Nickels, N. T. Hargrett-Bean, M. E. Potter, T. Endo, L. Mayer, C. W. Langkop, C. Gibson, R. C. McDonald, R. 
T. Kenny, N. D. Puhr, P. J. McDonnel, R. J. Martin, M. L. Cohen, and P. A. Blake. 1987. Massive outbreak of antimicrobial-resistant salmonellosis traced to pasteurized milk. J. Am. Med. Assoc. 258:3269-3274

SAS Institute. 2002. SAS User's Guide: Statistics. Version 9.1. SAS Inst., Inc., Cary, NC.

Schlech, W. F. 1997. Listeria gastroenteritis - Old syndrome, new pathogen. N. Engl. J. Med. 336:130-132

Sweeney, R. W. 1996. Transmission of paratuberculosis. Vet. Clin. North Am. Food Anim. Pract. 12:305-312.

USDA. 2002a. Part I: Reference of dairy health and management in the United States, 2002. \#N377.1202. USDA:APHIS:VS, CEAH, National Animal Health Monitoring System, Fort Collins, CO.

USDA. 2002b. Part II: Changes in the United States dairy industry, 1991-2002. \#N388.0603. USDA:APHIS:VS, CEAH, National Animal Health Monitoring System, Fort Collins, CO.
USDA. 2002c. Part III: Reference of dairy cattle health and health management practices in the United States, 2002. \#N400.1203. USDA:APHIS:VS, CEAH, National Animal Health Monitoring System, Fort Collins, CO.

Wapenaar, W., G. Van Schaik, P. Leids, L. Denney, Y. H. Schukken, S. M. Stehman, and J. Huntley. 2003. NYSCHAP Johne's disease module, a program to change management of dairy farms to reduce Johne's disease prevalence. Bovine Pract. 37:23-29.

Zdanowicz, M., J. A. Shelford, C. B. Tucker, D. M. Weary, and M. A. G. von Keyserlingk. 2004. Bacterial populations on teat ends of dairy cows housed in free stalls and bedded with either sand or sawdust. J. Dairy Sci. 87:1694-1701.

Zwald, A., P. L. Ruegg, J. B. Kaneene, L. D. Warnick, S. J. Wells, C. Fossler, and L. Halbert. 2004. Management practices and reported antimicrobial usage on conventional and organic dairy herds. J. Dairy Sci. 87:191-201. 